\title{
Bruno Restif, Les censures de la faculté de théologie de Reims à l'époque du cardinal de Lorraine. Répression du protestantisme, contrôle du livre, conflits intra- catholiques et normalisation post-tridentine
}

\section{Gianmario Cattaneo}

\section{OpenEdition}

\section{Journals}

Edizione digitale

URL: https://journals.openedition.org/studifrancesi/21116

DOI: $10.4000 /$ studifrancesi. 21116

ISSN: 2421-5856

Editore

Rosenberg \& Sellier

\section{Edizione cartacea}

Data di pubblicazione: 1 décembre 2019

Paginazione: 565

ISSN: 0039-2944

\section{Notizia bibliografica digitale}

Gianmario Cattaneo, «Bruno Restif, Les censures de la faculté de théologie de Reims à l'époque du cardinal de Lorraine. Répression du protestantisme, contrôle du livre, conflits intra-catholiques et normalisation post-tridentine», Studi Francesi [Online], 189 (LXIII | III) | 2019, online dal 01 mars 2020, consultato il 12 novembre 2021. URL: http://journals.openedition.org/studifrancesi/21116 ; DOl: https://doi.org/10.4000/studifrancesi.21116

Questo documento è stato generato automaticamente il 12 novembre 2021.

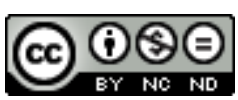

Studi Francesi è distribuita con Licenza Creative Commons Attribuzione - Non commerciale - Non opere derivate 4.0 Internazionale. 


\title{
Bruno Restif, Les censures de la faculté de théologie de Reims à l'époque du cardinal de Lorraine. Répression du protestantisme, contrôle du livre, conflits intra-catholiques et normalisation post-tridentine
}

\author{
Gianmario Cattaneo
}

\section{NOTIZIA}

Bruno Restif, Les censures de la faculté de théologie de Reims à l'époque du cardinal de Lorraine. Répression du protestantisme, contrôle du livre, conflits intra-catholiques et normalisation post-tridentine, «Bibliothèque d'Humanisme et Renaissance» LXXXI, 1, 2019, pp. 7-42.

1 L'ultimo numero della rivista «Bibliothèque d'Humanisme et Renaissance» contiene un contributo di Bruno Restif dedicato alle censure pronunciate dalla Facoltà di Teologia di Reims nel corso del Cinquecento. Finora gli studi si sono concentrati quasi esclusivamente sull'attività censoria della Sorbona, quindi un valore notevole assume la scoperta di Restif, il quale ha individuato presso la Bibliothèque Municipale di Reims una copia settecentesca delle censure promulgate a Reims nel terzo quarto del Cinquecento. Questi testi sono in parte inediti, se si eccettuano alcuni stralci pubblicati nel 1726 da Charles du Plessis d'Argentré, che dovrebbe essere colui che allestì la copia attualmente conservata a Reims.

2 L'Università di Reims fu fondata nel 1548 per volere del cardinale Carlo di Lorena, su cui Restif insieme a J. Balsamo e Th. Niklas ha curato l'importante raccolta di studi Un 
prélat français de la Renaissance. Le cardinal de Lorraine, entre Reims et l'Europe. I documenti riguardano gli anni 1557, 1558, 1559, 1564, 1566, 1569, 1570 e 1572, e sono analizzati da Restif prima dal punto di vista linguistico, poi contenutistico. L'obiettivo di queste censure era prevenire la diffusione del protestantesimo a Reims e le interpretazioni deviate dei dogmi cristiani, e per questo motivo interessarono soprattutto i testi degli autori protestanti, come Pierre Viret. Nel 1566, inoltre, la facoltà censurò alcuni capitoli contenuti nelle opere del celebre polemista Gentien Hervet, che nel 1562 si era spostato da Orléans a Reims al seguito di Carlo di Lorena. Infine, tramite le censure del 1570 e 1572, il vicario generale dell'arcivescovo, Pierre Rémy, cercò di regolarizzare il clero di Reims sulla base della riforma tridentina.

3 Da questo articolo, emerge quindi un nuovo quadro a proposito dell'attività censoria nella Francia del Cinquecento: infatti, «la faculté de théologie de Reims est la seule faculté française à oser braver ouvertement la prétention monopolistique de la faculté de théologie de Paris dans le domaine de l'activité censoriale» (p. 39). 